\title{
The Development Strategy of Community Education for Improving the New Generation of Migrant Workers' Psychological Capital -Based on the Idea of Educational Equity
}

\author{
Wang Simin ${ }^{1, a}$, Tang Yaner ${ }^{2, b}$ \\ ${ }^{1}$ College of Public Administration of Jinan University, Guangzhou \\ 2 Education College of Jinan University, Guangzhou \\ a wangsiminc607@163.com b tye@jnu.edu.cn
}

\begin{abstract}
Key words: New generation of migrant workers; Community education; Psychological capital; Educational equity
\end{abstract}

Abstract. The ensuring of the educational fairness for vulnerable groups has been one of the hot spots in the academic researches and education reforms. As the mainstay of economic development, the new generation of migrant workers has made great contribution to the urban development. However, they are at a disadvantage in accessing the social public resources owing to their relatively low social status which causes their psychological imbalance. Through the empirical investigations, the article combs the new generation of migrant workers' characteristics and their psychological problems, draws the conclusion that education has a positive correlation to their psychological levels. Therefore, community education should play a fair role to help them integrate into urban society as quickly as possible.

\section{Introduction}

The new generation of migrant workers, are laborers born after1980, working outside from middle and later periods of the1990s, but they are registered as farmers in their agricultural household. [1] " The China's floating population Development Report 2015" shows that the China's floating population has increased to 253 million at the end of 2014[2], and "the $13^{\text {th }}$ Five-Year plan for National Economic and Social Development(the $13^{\text {th }}$ Five Year Plan)" also urges the acceleration of urbanization. With urbanization and socio-economic development, the main part of mobility population is the new generation of migrant workers from rural areas who play an increasingly significant role in urban construction. However, owing to the existing mechanism and institutional obstacles, they do not completely adapt to the urban life. The discriminations make it hard to realize their social integration, changing destiny and improving conditions. What's more, their educational and vocational skills still lag far behind the needs of the urban labor market, makes them lack a sense of security and stability, instead it fills them full of anxiety and fear.

In order to cultivate the confident, optimistic, hopeful, resilient quality of the new generation of migrant workers, strengthening the social support and seeking the educational fair ways to enhance their psychological capital is an important issue. Based on this perspective, Community education could provide fair educational opportunities for all groups, especially for the new generation of migrant workers, so that they can receive education flexibly. More significantly, community education makes up for the deficiencies caused by the institutional education and elimination mechanism.

From the existing literature, some scholars realize that "new generation of migrant workers has the strong experience in sense of injustice at social level" [3], some put forward that community education should play an important role in supporting the disadvantaged groups [4], and scholars pay various degrees of attention to new generation of migrant workers' psychological capital home and abroad. There are abundant researches in the field of structure and impact of psychological capital. Luthans designed Psychological Capital Questionnaire (PCQ, containing 24 questions) and analyzed the four dimensions: hope, optimism, self-efficacy, resilience. These conclusions have a wide range of application [5].Some literati believe that some factors that affect psychological formation, including organization support, economic factors, self-realization, human relationships, 
health status, family factors and so on. Nevertheless those researches mainly focus on the analysis of the elements of foreign psychological capital, it is still worthwhile to further explore the China's new generation migrant workers' psychological capital and its promotion strategy. Therefore, based on the results of empirical investigation, the study makes connection of community education and migrant workers' psychological capital, explores the development of community education for the goal of promoting city integration and improving their psychological capital.

\section{Survey Method and Sampling}

Taking new generation of migrant workers under employment in Guangdong Province as samples, two questionnaires are conducted in this study. The surveyors select respondents randomly, and it covers most of the areas that appeal to new generation of migrant workers in Guangdong Province, namely, Guangzhou, Shenzhen, Zhongshan, Foshan, Huizhou and Zhanjiang Districts. The one is the analysis of issues concerning Chinese new generation of migrant workers characteristics and their mental health. We handed out 350 copies of questionnaire and 303 copies were valid. The other is to explore the new generation of migrant workers' psychological capital levels, with effective recovery rate of $84 \%$.

\section{Data Description and Analysis}

\subsection{The First Analysis}

3.1.1 Distinctive Group Characteristics. Compared with the traditional migrant workers, the new generation shows different characteristics so it is necessary to comb their distinctive characteristics.

Table 1 The new generation of migrant workers characteristics

\begin{tabular}{|l|l|}
\hline Education background & $\begin{array}{l}\text { Half of the respondents receive secondary education } \\
\text { Low participation of continuing education }\end{array}$ \\
\hline Job & Engaged in different industry \\
\hline Wage & Lower than the average wage level \\
\hline Mobility & Changing jobs frequently \\
\hline Aim & Having a strong will to settle down in city \\
\hline
\end{tabular}

It is learned in the survey that for the young migrant workers from Guangdong Province, $50.7 \%$ of them received junior high school or senior school education, while only $7.9 \%$ of them received Bachelor degree or above, and only $26.3 \%$ participants pursue continuing education. Most of the young migrant workers have been working in the city for 2 to 6 years, up to $50.9 \%$. In terms of economic level, the number of migrant workers with yearly income of less than 60000 yuan reaches to $83.9 \%$, which is lower than the average wage level 63241 yuan in 2015 . Nearly $67.1 \%$ of the new generation migrant workers desire to settle in the city. As for the mobility, job hopping with the frequency of 1 to 6 times in a year is up to $48.9 \%$, which indicates low stability of employment.

3.1.2 Weak Social Support and Prominent Mental Health Problems. Over the years, community construction has come to a new stage of development by leaps and bounds. By the end of 2015, it had a total of 100000 community residents' committees and 581000 village committees, which demonstrates the community service and quality have significantly improved. While according to the survey results, new generation of migrant workers seldom get help and services from community, which is contradictory to their strong will of obtaining support.

Faced with differences of interests and inequality of opportunity in getting help, new generation of migrant workers are likely to be infected by discontent and resentment, and even lead to retaliatory crime. In the survey, $78.4 \%$ of respondents often have psychological problems, such as mental depression, disinclination, irritability and nervousness, which is against their city integration.

3.2 The Second Analysis. The research redesigned the psychological capital questionnaire which makes reference to PCQ written by Luthans. By adopting the analytical method of SPSS software statistics, the total scale's KMO value is 0.898 , along with significance less than 0.001 , shows that the data is suitable for factor analysis. From the factor analysis results, optimism, hope, 
resilience and confidence are four dimensions of psychological capital. What's more, the study shows that education has a positive effect on the psychological capital. The analysis is shown in table 2 .

Table 2 Correlation analysis of new generation peasant workers' psychological capital and education ${ }^{11}$

\begin{tabular}{|c|c|c|c|c|}
\hline \multirow[t]{2}{*}{ Dimension } & \multirow[t]{2}{*}{ contribution rate } & \multirow[t]{2}{*}{ The items of each dimension } & \multicolumn{2}{|c|}{ A4 Education } \\
\hline & & & Pearson & Significance \\
\hline \multirow{4}{*}{ 1Optimism } & \multirow{4}{*}{$27.143 \%$} & B1 I will solve work problems anyway & $.167^{* * *}$ & .000 \\
\hline & & B15 I feel very happy every day & .034 & .315 \\
\hline & & $\begin{array}{l}\text { B17 I feel bad things will soon pass away when } \\
\text { I am in trouble }\end{array}$ & $.109^{*}$ & .002 \\
\hline & & $\begin{array}{l}\text { B23 I can auicklv adjust the mood when } \\
\text { encounter bad things }\end{array}$ & $.102^{*}$ & .003 \\
\hline \multirow{3}{*}{2 Hope } & \multirow{3}{*}{$8.409 \%$} & $\begin{array}{l}\text { B6 Even if I am resourceful, something will go } \\
\text { wrong(R) }\end{array}$ & -.055 & .099 \\
\hline & & $\begin{array}{l}\text { B7 I often in a loss when I meet difficulties in } \\
\text { work(R) }\end{array}$ & -.079 & .019 \\
\hline & & $\begin{array}{l}\text { B19 I have little or no hope of the current } \\
\text { job(R) }\end{array}$ & -.202 & .003 \\
\hline \multirow{4}{*}{ 3Resilience } & \multirow{4}{*}{$6.085 \%$} & $\begin{array}{l}\text { B2 No matter how bitter and tired the work is, I } \\
\text { will stick to it }\end{array}$ & $.093^{*}$ & .006 \\
\hline & & $\begin{array}{l}\text { B4 I'll patient to deal with the trivial } \\
\text { multifarious affairs at work }\end{array}$ & $.108^{* * *}$ & .001 \\
\hline & & B22 I am energetic to complete the work & $.120^{* * *}$ & .001 \\
\hline & & $\begin{array}{l}\text { B24 I am gradually realizing the goal of being a } \\
\text { good staff }\end{array}$ & $.091^{* * *}$ & .009 \\
\hline \multirow{3}{*}{ 4Cofidence } & \multirow{3}{*}{$5.659 \%$} & $\begin{array}{l}\text { B3 No matter how hard I couldn't finish the } \\
\text { task (R) }\end{array}$ & $-.091^{* *}$ & .007 \\
\hline & & B9 I can't complete the work efficiently $(\mathrm{R})$ & $-.068^{*}$ & .042 \\
\hline & & $\begin{array}{l}\text { B11 I doubt my work ability since entering new } \\
\text { cities (R) }\end{array}$ & $-.076^{*}$ & .024 \\
\hline
\end{tabular}

3.2.1 Hope, Resiliency, Optimism are in the Low Level. From the factor analysis sequence, we can know that the highest psychological capital is optimism, the second is hope, followed by resilience, and the final one is confidence. The first investigation has drawn the conclusion that there is a conflict between ideal and reality. For the new generation of migrant workers, learning, achieving personal value and enhancing the social status become their ideal pursuit. But the reality of insufficient social supporting makes them difficult to integrate into the city with dignity. Faced with the great contrast between ideal and reality, they can't have the strong will and powerful resilience to live in the city. Therefore, great efforts should be taken to improve the level of these three lower dimensions.

3.2.2 Education and Psychological Capital have Positive Interrelated Relationship. As can be seen from the Table 2, except for B15 and B6, whose significance levels are above 0.05, the rest of the items of the psychological capital and education have positive correlation. In other words, the new generation of migrant workers' psychological capital level can be improved through education, so education, especially community education can be the ideal platform to improve their psychological capital.

\section{Recommendations}

Taking the new generation of migrant workers' special personal characteristics into account, we find out that community education meets their different needs, especially the improvement of psychological capital. It provides an effective learning platform for migrant workers to participate in continuing education and supply some useful employment skills and information for them. Therefore, in the long term, it is required to explore the sustainable recommendations of community education, for improving their comprehensive quality and psychological capital.

\subsection{Expanding the Social Support, Strengthening the Management of Community}

\footnotetext{
$\mathrm{R}$ is the reverse item.
} 
Education. The government should play a dominant role in community education's organization and management. Relevant government departments should promptly transfer relevant information of training, and take on the evaluation of training quality. It is worth mentioning that on July 29, 2016, the education and other nine ministries jointly launched the file of "Further advancing the development of community education" [6]. Fully affirmed the significance of providing educational support and service for migrant workers, the file will help to promote the community education reform. In the near future, great efforts will be paid to its legalization and standardization.

4.2 Overcoming the Obstacles that Hindering the Development of Community Education. The purpose of migrant workers participating in community education is to promote self transformation and rebuilding. However, new generation of migrant workers are restricted by many factors, such as education and training system, funds, individual difference, teaching insurance, and learning content, so overcoming the obstacles is the foundation of promoting its development. First of all, building a flexible, open, suitable and efficient training system is an important subject. Secondly, perfecting the fund guarantee system, expanding the funding and encouraging multidimensional investment should be regarded as necessary issues. Besides, teaching supervision is one of the main measures to guarantee and promote the quality of community education. It is required to improve teachers loyalty, to solve the special needs of migrant workers. Only in that way, the positive interaction between teachers and students can be realized.

4.3 Improve the New Generation of Migrant Workers Enthusiasm for Learning. The questionnaire investigation shows that education has a positive effect on migrant workers' psychological capital, while they still have not realized the significance of study. So it is necessary to actively guide migrant workers to increase their consciousness of learning and to keep lifting the employment ability. In practice, the whole community should use offline and online media to site publicity and promotion, which can motivate the migrant workers to "learn for the city survival, learn for the improvement of life and learn for the career development".

4.4 Developing Appropriate Mode of Community Education. Due to the new generation of migrant workers individual differential needs, community education should design the effective ways to provide the appropriate education content. For one thing, the research about how to set the migrant workers' training courses as the compulsory courses should be carried out. Matching the community course with the migrant workers' cognitive ability correctly is a solution to meet their requirement of life and employment. For another, related institutions should integrate the educational resources, with the goal of implementing the community course training for migrant workers. In addition, community education should give out certification of vocational skills for migrant workers and schedule examinations of training performance. In this way, their employment ability and basic cultural foundation can be enhanced comprehensively.

4.5 Building the Platform of "Internet +" to Create A Digital Learning Environment. In 2015, Premier Li Keqiang put forward the concept of "Internet +". "Internet +" has driven the innovation and development of education, and effectively promoted the digital education construction. Therefore, community education should make full use of network information technology to construct the digital learning platform and provide some network courses. Network courses construction aims to achieve the goal of sharing high-quality educational resources effectively and promoting the spread of information technology as an important teaching measure. In addition to some essential training courses, positive mental health education and online counseling mechanism should be involved in the digital platform. The new generation of migrant workers who suffer from mental problems can correctly deal with the depression and dissatisfaction after anonymous psychological counseling, which will accelerate their integration.

4.6 Setting up the Long-Term Effective Mechanism of "The Credit Bank". According to survey results, the migrant workers have strong will of settling in the city, but low stability is adverse to their continuing learning. Setting up the long-term effective mechanism of "the credit bank" can solve this contradiction and escort the financial and flexible mechanism of training. Credit Bank is designed to record and accumulate credit value of learners received from all educational and technical trainings [7]. New generation of migrant workers acquiring related 
specialty and curriculum are not restricted by time and place. Meanwhile, the flexible options are available regardless of the varieties and interest. There is no double that the credit bank will actively attract the migrant workers to participate in the community education, and the construction is a complex and profound project which calls for great efforts in the long run.

\section{Conclusions}

Community education is an important means to achieve educational equity, it meets the new generation of migrant workers' diversified educational and psychological needs. All in all, community education should play a significant role in improving their capability and psychological capital, for achieving the goal of city integration.

\section{Acknowledgements}

Source of Funding: Research for Social Support Mode of the New Migrant Workers Based on Psychological Capital, National Social Science Foundation (China), No.16BSH092.

\section{References}

[1] WU Y. Discussion on characteristics of new generation of migrant workers[J].Dongyue Tribune, 2009, 30(8):57-59. (in Chinese).

[2] Information: http://ex.cssn.cn/dybg/gqdy_gqcj/201511/t20151112_2577235_2.shtml/2016-7-8.

[3]Long Shuqin , Feng Xiaotian, In: Social Structure, Reference Group and Sence of Injustice among New Generation of Migrant Workers, edtied by Beijing: Youth Studies(2015)

[4] Chen Nailin Vice-chairman, Chinese Adult Education Association. Supporting Disadvantaged Group through Education_-An Important Task of Community Education Development[A]. 2006:2.

[5] Luthans F, Avolio B J, Walumbwa F O, and Li W. The psychological capital of Chinese workers: Exploring the relationship with performance. Management and Organization Review, 2005,1: 247 269.

[6]Information:http://www.moe.edu.cn/jyb_xwfb/xw_fbh/moe_2069/xwfbh_2016n/xwfb_160729/1 60729 sfcl/201607/t20160729_273303.html/2016-08-15.

[7] Zezhao Liu, Haifeng Tian. Educational Credit Bank System Construction for Provincial Level in China: Target, Framework and Mechanism__A Case From Shaanxi Province [A]. 2013:6. 